Message Framing in P2P Lending Relationships

Jin Huang

$\mathrm{PhD}$ Candidate

Essex Business School, University of Essex,

Elmer Approach,

Southend-on-Sea, SS1 1LW,

United Kingdom.

Email: jh17315@essex.ac.uk,

T: +44 (0) 1702328423.

Vania Sena (corresponding author), PhD

Chair in Entrepreneurship and Enterprise

The University of Sheffield,

Sheffield University Management School,

Conduit Road,

Sheffield, S10 1FL,

United Kingdom.

T: +44 (0)114 222 3232,

Email: v.sena@sheffield.ac.uk.

Jun Li, PhD

Senior Lecturer in Entrepreneurship

Essex Business School, University of Essex,

Elmer Approach,

Southend-on-Sea, SS1 1LW, 
United Kingdom.

T: +44 (0) 1702 328423,

Email: junli@essex.ac.uk.

Sena Ozdemir, $\mathrm{PhD}$

Senior Lecturer in Marketing

Lancaster University,

Lancaster University Management School,

Charles Carter Building,

Lancaster, LA1 4YX,

United Kingdom.

T: +44 (0)1524 593053,

Email: s.ozdemir@lancaster.ac.uk

Accepted version for publication in Journal of Business Research 


\title{
Message Framing in P2P Lending Relationships ${ }^{1}$
}

\begin{abstract}
This paper investigates whether language and associated message framing (low-cost signal) can provide a solution to the risks generated by asymmetric information in $\mathrm{P} 2 \mathrm{P}$ lending, drawing on the signalling and message-framing theories. First, it examines the extent to which message framing is associated with funding outcomes in the context of P2P lending; second, it investigates whether positive message framing reinforces the positive impact of credit ratings (high-cost signal) on funding outcomes. Our analysis is conducted on a dataset of 33028 listings of potential borrowers from a Chinese P2P lending platform using the Heckman selection models. We find that the use of positively framed messages is positively associated with positive funding outcomes and enhances the positive impact of the credit ratings on funding outcomes. Our results contribute to the literature on the effectiveness of low-cost signals in of Internet-based interactions while highlighting complementarities between different types of signals in P2P lending.
\end{abstract}

Keywords: Signalling Theory; Message Framing; P2P Lending.

Type: Research Paper.

1 Acknowledgements: The first author is grateful to the China Scholarship Council (CSC) Scholarship (Grant number: 201708450079) for financial support. 


\section{Introduction}

Financial technologies ('FinTechs') are changing the face of global finance by integrating finance and technology in ways that disrupt traditional financial models while providing an array of new services to businesses and consumers. The hybridization of technology with the conventional processes of finance has replaced traditional intermediation models while leveraging alternative business models that take advantage of the new technologies. Importantly, Peer to Peer lending (after that, P2P lending) has given rise to new models of financial intermediation where borrowers can access funds for individual or business purposes (Lin et al., 2013) without additional guarantees. P2P lending is usually defined as an unsecured lending relationship that uses an online platform to facilitate money exchanges between borrowers and lenders (Lin et al., 2013; Bachmann et al., 2011; Tao et al., 2017). China is the world leader by any indicator. The first P2P platform, PPdai, was established in 2007 and the market began to explode in 2013. According to data collected by P2P consultant WDZJ.com, the trading volume of the Chinese P2P lenders expanded to 127 times its original size, from \$3 billion in 2012 to $\$ 381$ billion in November 2017. Meanwhile, total outstanding loans grew 221 times, from $\$ 0.8$ billion in 2012 to $\$ 177$ billion in November 2017 (Figure 1).

\section{--- INSERT FIGURE 1 ---}

Three main factors explain the popularity of P2P platforms in China (Huang, 2018; Mittal and Lloyd, 2016). The first one is the supply shortage in the formal financial markets, especially for small- and medium-sized enterprises (SMEs) and poor households. In China, state-owned 
banks tend to overlook small borrowers (Fungacova and Weill, 2014) while giving priority to state-owned companies; besides, the absence of a sophisticated system to assess consumers' credit-risk adds to the banks' reluctance to lend to individuals (Boyreau-Debray and Wei, 2005). Second, the regulatory environment has been very tolerant of alternative finance providers. Lack of regulation in the industry can be explained by the widely held belief that alternative providers can produce useful innovations the whole financial sector could benefit from (Wang et al., 2016). The third factor is the rapid growth of internet-based startups in China. These new ventures find it difficult to borrow from traditional financial intermediaries due to their limited resources and unstable revenues (Salomon, 2018).

An essential question around $\mathrm{P} 2 \mathrm{P}$ lending is how these new models of financial intermediation mitigate the risks associated with asymmetric information. Traditionally, financial institutions deal with asymmetric information on the quality of the borrowers in two ways: they can build long-term relationships with customers (so that "soft" information on applicants is collected over time). Alternatively, they can develop credit score systems that rely on the collection of "hard" information from applicants through transactional data (Landström, 2017). However, these two risk-mitigation strategies are not entirely viable in the context of the P2P platforms. Typically, these are structured in such a way that long-terms relationships with customers are not feasible (as they have not been operating for a long time). At the same time, platforms may not be in a position to collect "hard" information on their clients efficiently. In other words, "centralized" platform-led solutions to the asymmetric information problem are not viable.

Some authors have argued that language and associated message framing (two cheap signals) can provide a solution to the risks generated by asymmetric information as they would 
help lenders to distinguish between high and low-quality borrowers (Anglin et al., 2018; Loewenstein et al., 2014). Message framing is usually considered a low-cost signal ${ }^{2}$ (Anglin et al., 2018) which can be useful when lenders lack sufficient experience and knowledge about an investment (as in the context of P2P lending) and assessing high-cost signals (such as credit ratings) may be challenging (Anglin et al., 2018). However, previous studies have found mixed results about the effectiveness of message framing in the context of Internet-based interactions. For instance, Ludwig et al. (2013) have shown that message framing may not always be necessary when evaluating online reviews; at the same time, Sparks and Browning (2010) observed the significant effects of positive and negative message framing of online reviews. Furthermore, Anglin et al. (2018) find that language communicated through the framing of messages may be an effective low cost (cheap) signal, specifically in the case of crowdfunding. Additional studies examining the role of low-cost signals in the context of P2P funding have focused on a small set of signals such as photographs, message lengths, text descriptions, and spelling mistakes (Dorfleitner et al., 2016; Duarte et al., 2012). However, these papers have provided limited insights into the impact of message framing on a lender's decision in the context of $\mathrm{P} 2 \mathrm{P}$ lending. There is still a need to address the inconsistent empirical findings on the role of message framing in internet-based interaction contexts. This study suggests that positive message framing may overcome the challenges of assessing the qualities of borrowers when long-term relationships are not possible. It also indicates that message-framing can provide complementary knowledge when evaluating costly signals such as their credit ratings. In this context, this study posits that message framing referring to the cognitive and affective attributes

\footnotetext{
${ }^{2}$ According to signalling theory, signals can be either costly (i.e. a certain amount of time and effort is required to be able to generate and send the signal) or cheap (i.e. minimal effort is needed to create and transmit the signal).
} 
of borrowers such as their trustworthiness can play a significant role in complementing high-cost signals such as their credit ratings. The study contributes to previous research on P2P lending by investigating not only the influence of low-cost signals through message framing but also the complementary role of a high-cost signal in affecting the funding decisions within a P2P lending setting (Dorfleitner et al., 2016; Duarte et al., 2012; Guo et al., 2016; Davis and Allison, 2013). While message framing may mitigate the challenges of asymmetric information in the context of P2P lending, it may also provide complementary information when evaluating costly signals such as their credit ratings because it allows for additional explanation and meaning to the numerical scores. From a practice viewpoint, message framing is an important issue to investigate in $\mathrm{P} 2 \mathrm{P}$ lending settings because of the increasing importance of $\mathrm{P} 2 \mathrm{P}$ lending platforms for obtaining consumer credits (Dorfleitner et al., 2016; Duarte et al., 2012; Guo et al., 2016).

Against this background, drawing on the signalling and message-framing theories, the purpose of the paper is two-fold. First, it examines to what extent message framing is correlated to funding outcomes in the context of P2P lending using insights from the signalling and message-framing theories. Second, it assesses how message framing complements credit ratings in conveying information on the borrowers and influence funding outcomes. The study contributes to previous research on $\mathrm{P} 2 \mathrm{P}$ lending by investigating not only the impact of message framing but also the complementarity among different signals (i.e. high-cost signals and low-cost signals) in P2P lending (Dorfleitner et al., 2016; Duarte et al., 2012; Guo et al., 2016; Davis and Allison, 2013).

Our empirical analysis is conducted on a dataset of 33028 listings drawn from the leading Chinese P2P platform, Renrendai. The results suggest that positive message framing is positively 
associated with the likelihood of funding success but not with the number of bids a project receives. Also, message framing enhances the impact of the borrowers' credit ratings on funding success.

The structure of the paper is as follows. Section 2 develops our set of hypotheses on message framing and funding outcomes. The empirical methodology and the data are presented in Section 3. The empirical results are discussed in Section 4, while the robustness tests are presented in Section 5. Finally, a discussion on the implications of the results is presented in Section 6, while some concluding remarks are offered in Section 7.

\section{Theoretical Background}

Signalling theory focuses on the mechanisms that may reduce asymmetric information between two parties. More specifically, it focuses on whether and how an informed sender (e.g. a borrower) communicates information (i.e. a signal), and how a receiver (e.g. potential investor) interprets the signal (Lee et al., 2016). Communication between parties can take place either via high-cost signals - based on observable actions or qualities - and via low-cost signals mostly relying on words or cheap talk (Cheung et al., 2014). Traditionally, signalling theory argues that high-cost signals are more effective in solving potential asymmetric information problems than low-cost signals (Connelly et al., 2011). In this context, evaluating quality from a cheap signal can be challenging (Anglin et al., 2018; Farrell and Rabin, 1996; Steigenberger and Wilhelm, 2018) as there is little or no explicit cost to acquire and transmit, and therefore can be of limited use. For instance, Chen et al. (2009) find that entrepreneurial passion (a low-cost signal) is an intangible and hard-to-measure quality of potential entrepreneurs which however does not help 
them to acquire external funding through venture capital. Thus, venture capitalists prefer to rely on costly signals to decide on the quality of the entrepreneurial venture.

Nevertheless, low-cost signals send through message framing are particularly useful when the audience lacks sophistication, and high-cost signals can be confusing to collect (Danilov and Sliwka, 2016; Marti and Balboa, 2007; Loewenstein et al., 2014). Both cases can be relevant to the case of $\mathrm{P} 2 \mathrm{P}$ platforms which do not collect data on credit history or have no information on borrowers other than those shared voluntarily at the moment of the application (Anglin et al., 2018). In these cases, message framing may be the most critical low-cost signal that potential borrowers may have to convince lenders to support the project (Anglin et al., 2018; Steigenberger and Wilhelm, 2018). The literature on message framing suggests that consumers are strongly influenced by positively framed messages (Bester and Jere, 2012; Maheswaran and Meyers-Levy, 1990). As opposed to offline contexts relying on verbal and facial communication, in online environments, users frame messages through textual interactions (Maheswaran and Meyers-Levy, 1990). Particularly, to produce favourable responses, users need to use positive language exuding confidence, credibility, trustworthiness, and optimism (Aktaet al, 2016; Avey et al., 2011; Davis et al., 2017; Martens et al., 2007). This view is supported by previous research on brands showing that when brands fail to transmit positive signals about their characteristics and quality, customers are likely to dismiss their products (Besharat, 2010).

Signalling theory can be complemented by message framing theory in the sense that the way the message is framed will act as a signal; in turn, this may influence the receiver's (i.e. investor's) actions (Lee and van Dolen, 2015) and its decisions. When applied to a P2P lending context, positive message framing may be correlated with funding success as it may facilitate the 
evaluation of high-cost signals (like credit ratings) (e.g., Anglin et al., 2018; Ahlers et al., 2015; Courtney et al., 2017).

\subsection{Hypothesis Development}

Trustworthiness is an individual attribute that reduces transaction costs and provides relational advantages in exchange relationships (Dyer and Chu, 2003). Trust can be either cognitive or affective. Cognitive trust emerges from the perceived ability and competence of the other party while affective trust derives from positive feelings and caring motivations for the other party (Dowell et al., 2015). In this sense, a positively framed message can stimulate both cognitions and emotions in the trusting party (or trustor). In other words, the cognitive implication of a positively framed message may suggest that the borrower knows what s/he is doing. In other words, they can identify their own funding needs and handle the loan. A positively framed message may be a signal that the borrower will not behave opportunistically. Message framing is a low-cost signal which enables the cognitive and affective assessment of the borrower's individual qualities (such as ability and reliability). Framing has been extensively studied recently as an essential mechanism to gain support from an audience. In other words, framing allows a message to stand out and therefore to be noticed; however, the literature (in particular the one related to behavioural economics) has pointed out that framing motivates the audience to act towards a specific goal. More recently, a few authors have started to focus on how a message can be framed in the context of a written text ${ }^{3}$ : the general conclusion is that in this case, written cues that are directly related to the critical concept in the frame can be helpful in the case of written text. Öhman et al. (2001) show that emotions communicated through

\footnotetext{
${ }^{3}$ See Defazio et al., 2020, and literature therein.
} 
language can drive attention by generating positive sentiments towards an individual or a situation. "Sentiment" is defined as a person's positive (or negative) emotional disposition towards another person or object. For example, sentiments of trustworthiness enable the trustor to establish emotional bonds with the trustee (Dowell et al., 2015). Thus, in general, positive sentiment may result in positive responses, whereas negative sentiments may elicit adverse reactions (Hsu et al., 2019). In the context of P2P lending, if the message framed in the description of the potential borrower (or of a project) conveys the notion that the borrower is trustworthy, then the project will receive attention from potential lenders who may be interested in funding the project; alternatively, borrowers can enhance their trustworthiness by showing concern and care by making timely repayments of loans to the lenders. The sentiment expressed by potential borrowers when describing a project represents relevant information which can affect lenders' decisions. Dorfleitner et al. (2016) support this view by observing that specific keywords (attached to particular sentiments) may be positively associated with the funding success of P2P projects. Studies on message persuasion suggest that affective and cognitive states of persuasion are intertwined rather than separate (Homer and Yoon, 1992). On the one hand, affective framing of messages through positive language may prompt the cognitive involvement of the receivers (Lee and van Dolen, 2015). On the other hand, messages triggering cognitive beliefs regarding trustworthiness can help to develop an affective state of trust (Johnson and Grayson, 2005). In terms of cognitive effects, positively framed messages have a direct effect on cognitive beliefs about the trustworthiness of a party (Claeys and Cauberghe, 2014). Indeed, positive language can convince receivers about a sender's trustworthiness in terms of its ability to achieve a particular goal (Newman et al., 2014), and control over the outcome (Luthans et al., 2004). In line with this view, previous studies have therefore 
highlighted that a message emphasizing the ability and competence of a trustee can be interpreted as a signal that can affect cognitive beliefs of the reader and can, therefore, influence its actions (Zhang and Buda, 1999; Ahlers et al., 2015). In line with this view, we can argue that an individual pays attention to rationally framed messages (Zhang and Buda, 1999). An emphasis on the ability and competence of a trustee would be interpreted as signals affecting cognitive beliefs and can, therefore, strongly impact the probability of funding success (Ahlers et al., 2015).

Message framing to convey competence and ability can be even more critical in low-trust countries such as China. At the personal level, "low trust" in the Chinese communities manifests itself in the lack of personal trust. Fukuyama (1995) suggests that culture is at the origin of "low trust" in China as individuals can almost only trust another person as longs as they have a personal connection with. At the societal level, "low trust" emerges as a lack of trust in the institutions and authorities; Ke and Zhang (2003) argue that weak institutions underlie the prevailing low institutional trust in China. In such institutional environments, the scope of trust cannot be easily extended beyond the number of people that are known personally (Fukuyama, 1995; Putnam, 2000). The pervasive phenomena of cheating, fakes and defaults (which can characterize $\mathrm{P} 2 \mathrm{P}$ platforms) in turn entrench personal and institutional distrust. In low-trust cultures such as China, investors need to be reassured about the trustworthiness of the other parties; in online P2P settings, message framing can help reduce the complexity in everyday life and substitute for the risks that are inherent in decisions or situations (Welter \& Smallbone, 2006). Thus, positive language as message persuasion can trigger cognitive beliefs which can lead to affective trust. Against this background, we posit that: 
Hypothesis 1. Framing the message so that it suggests the borrower is trustworthy is positively related to the likelihood of a project being funded.

In an environment with pervasive asymmetric information, making decisions based on one set of signals - either high cost or low cost - may be difficult. However, having access to different types of signals may not solve the problem (Plummer et al., 2016) since, taken together, they may provide contradictory messages (Anglin et al., 2018). In such a situation, receivers implicitly rank the quality and clarity of the signals they receive and decide which signal they decide to rely on. In general, receivers would tend to attach more weight to high-cost signals than to low-cost signals as they tend to be more reliable than low-cost signals (Connelly et al., 2011). However, in the context of P2P lending, high-cost signals - including individual credit scores can be complemented by low-cost signals providing information on the quality of the potential borrower. P2P lending platforms tend to be noisy environments and therefore more (rather than less) information is required by lenders before they can make decisions; in this case, positive message framing can enhance the effectiveness of high-cost signals - such as credit rating (Anglin et al., 2018). For example, Davis and Allison (2013) show that while high-cost signals are associated with funding success, low-cost signals can enhance their signalling power by providing more information to funders. In other words, positive message framing may strengthen the impact that other signals have on the likelihood of receiving funding (Anglin et al., 2018). We, therefore, suggest that:

Hypothesis 2. Framing the message so that it suggests the borrower is trustworthy positively moderates the association between credit rating of the borrower as a costly signal and the likelihood of a project being funded. 


\section{Empirical Analysis}

\subsection{The Renrendai Platform}

For our empirical analysis, we use data extracted from an online P2P platform called Renrendai. This is one of the largest P2P platforms operating in China, and several studies have already used their data (Mi and Zhu, 2017; Tao et al., 2017 and Yao et al., 2018). Renrendai was established in 2010 by three graduate entrepreneurs (Zhang, Li, and Yang). Like the majority of Chinese P2P platforms, Renrendai does not offer Web 2.0 functionality (Liu et al., 2018) implying that investors can only see static listing information and are not able to exchange information with the borrowers ${ }^{4}$. Besides, Renrendai (and other Chinese P2P platforms) provide an offline authentication service to mitigate further asymmetric information that is originated by a purely online authentication. In particular, they all use in-house generated credit ratings (that use data submitted by the applicants at the moment of the application) to segment borrowers according to risk.

The loan application process set up by Renrendai is as follows. First, borrowers submit their application forms with their national ID number and other personal information. They need to specify the requested amount, the interest rate they would like to pay, the purpose of the loan (and its expected duration), and any other information they find helpful to their application. The platform will verify the information submitted by the applicants and assign a credit rating to each applicant, varying between HR (high risk) and AA (very safe). The loan application process adopted by Renrendai is very similar to that of other Chinese P2P platforms. In particular, they all use in-house credit ratings (generated using data submitted by the loan applicant at the moment of the application) to segment borrowers according to risk. At the beginning of the

\footnotetext{
${ }^{4}$ This is different from what happens in other countries. For instance, investors in Prosper (a US-based P2P platform) can communicate with the potential borrowers and potentially can elicit more information about their trustworthiness.
} 
operations, Renrendai adopted a purely online model similar to US platforms; however, they changed model after they merged with Ucredit ${ }^{5}$.

Renrendai uses two approaches to generate a credit rating and bills the resulting applications as two different investment products. They offer borrowers the choice of whether to use their offline verification services or not. If these are used, the application is billed as an offline verified investment product. Otherwise, the application is billed as an authenticity checked product. The respective processes are as follows:

Option one: the application submitted online $\rightarrow$ documents desk checked $\rightarrow$ A credit rating assigned $\rightarrow$ the application up online for bidding

Option two: the application submitted to a Ucredit's branch with a request for the use of offline verification services $\rightarrow$ documents checked and verified offline $\rightarrow$ the verified application transferred to Renrendai $\rightarrow$ a credit rating assigned $\rightarrow$ the application up online for bidding.

All borrowers recommended by Ucredit will be assigned A class credit rating when their applications are listed online. Credit ratings of non-offline verified applications range more widely. Renrendai charges borrowers with initial (one-off) service fees of $0 \%, 1 \%, 2 \%, 2.5 \%$, $3 \%, 4 \%$ and $5 \%$ for AA, A, B, C, D, E, HR loans, respectively. After that, they charge monthly management fees $0.55 \%, 0.60 \%, 0.65 \%, 0.70 \%, 0.75 \%, 0.80 \%$, and $0.88 \%$ for $\mathrm{AA}, \mathrm{A}, \mathrm{B}, \mathrm{C}, \mathrm{D}, \mathrm{E}$, HR loans respectively. Interest rates vary following the borrower's credit rating, ranging from $6 \%$

\footnotetext{
${ }^{5}$ Ucredit was founded in May 2011 in Shanghai by a team of entrepreneurs. Ucredit focuses on micro-financing to individuals and has a network of 300 branches in near 100 cities nationwide. Individuals can apply for microloans to Ucredit in four ways: a) Online application through Ucredit website; b) Online application using WeChat APP; c) Application in branches and d) Application through Ucredit customer services hotline. Ucredit does not list any loan applications on their website for investors to bid, although they accept online applications. Ucredit currently focuses on two products: Instant microloans that target individuals who have a credit line of up to RMB 300,000 for personal consumption, Elite microloans that target civil servants, policemen, doctors, lawyers, and employees in large state-owned enterprises and banks. Microloans to micro and small businesses do not appear to be their primary focus anymore.
} 
to $24 \%$. If the listing is unsuccessful, there is no fee for the applicants. Loans accessed through the Renrendai platform are all uncollateralized. The maximum duration of the loan is up to 3 years, and the size of the loan ranges between 3000RMB and 500,000RMB. Renrendai guarantees the loan will be paid back to lenders by the end of the loan. To do so, it has a reserve fund to cover possible defaults and late payment. The fund is topped up constantly by the service fees charged. If the platform fails to collect back the loan, a collection agency will step in, and the money eventually collected will be put into the reserve fund.

The data for our empirical analysis is retrieved from the Renrendai platform and refer to all the listings between 1 January 2015 and 31 December 2015. We only focus on the loans that will be used to fund a start-up-related activity (based on the listing title) ${ }^{6}$. There are 43824 listings in our dataset. After deleting missing values, our dataset consists of 33028 listings. Among them, 9020 listings are fully funded. Each listing has the full set of information available to potential lenders. These include: (a) the loan terms such as interest rate, loan amount, loan duration, (b) the credit rating assigned by the platform and (c) the applicant's demographic information such as gender, age, educational attainment, marital status, employment status, and personal income range.

Why should some applicants prefer online applications only if they are more likely to be downgraded and less attractive to investors? Since Ucredit does not charge loan applicants for the use of their offline verification services, the affordability of offline services is not a factor. Three potential explanations can be accessibility, risk-taking, and self-confidence. First, Ucredit has established its branches primarily in the first-tier cities (Beijing, Shanghai, Guangzhou, and Shenzhen) and in some second-tier cities (Chongqing, Dalian, Chengdu, Ningbo). This means

\footnotetext{
${ }^{6}$ Listing titles vary substantially and include (among the others) medical expenses, house purchasing, wedding ceremony preparation.
} 
that they are less likely to conduct the verification of applicants in cities they do not have branches. So, branch accessibility can be reasonably considered a factor that influences the takeup of offline services. Second, non-users of offline services are generally young (on average, they are 30 years old while the other group is 38 years old on average) and may be more willing to take a chance with online services if younger people are perceived to be more risk-taking.

Mature users may be more conservative than younger ones and thus are more likely to prefer offline services. So, risk-aversion may be a factor. Third, as opposed to users of offline services, non-users are less likely to own property and thus are less likely to have a mortgage and a car loan. As a result, the average loan they asked in the P2P platform is ten times smaller than what the other group has asked (RM B 5,279 against RMB 69,171). Indeed, their borrowing records suggest that non-users have a meagre success rate in loan applications. For every ten applications they made, they succeeded at the rate of 0.17 .

In contrast, for users, for every 1.2 applications, the success rate was 1.007. These figures suggest that individuals who do not use offline services have no collateral and no credit history, implying that they cannot have access to loans. Hence, offline services work like banks: individuals tend to avoid them if they know they have no chance of getting funds.

\section{--- INSERT FIGURE 2 ---}

\subsection{Empirical Model and Variables}

In our model, the propensity of a project to get funded (and the number of bids it attracts) is a function of the projects' characteristics (interest rate, amount requested, and maturity) as well as of the potential borrower's characteristics (namely its income, educational attainment, and 
age). To test whether H1 holds, we add the indicator of trustworthiness and the number of words used to describe the project among our independent variables. Importantly, borrowers who would not choose offline authentication have different characteristics from those who would. Hence, it is highly likely that factors that are correlated with the borrowers' decision to use offline services would be correlated with both the propensity to get funded and the number of bids, creating a sample selection bias. To correct for such a bias, we use the Heckman selection model to estimate our model (Heckman, 1979). The Heckman model has two steps: the first step is to estimate the likelihood of borrowers choosing offline authentication by applying a probit model to the whole sample, including all listings with and without offline authentication. In the second step, the sample is restricted to the listings without offline authentication. Both dependent variables, offline authentication, and funding success are dummy variables, and therefore we estimate a probit model with sample selection. STATA estimates the two equations simultaneously by using a maximum likelihood estimation approach (Andres, 2014).

Our empirical model is as follows:

Prob(NonOffline $=1)=\alpha_{0}+\alpha_{1}$ Mortgage $+\alpha_{2}$ Carloan $+\alpha_{3}$ Branch $+\alpha_{4}$ Age + $\alpha_{5}$ Income $+\alpha_{6}$ Educational Attainment

Prob(FundingSuccess $=1)=\beta_{0}+\beta_{1}$ LnWordCount $+\beta_{2}$ Trust $+\beta_{3}$ Trust $*$ Credit Rating $+\beta_{4}$ Credit Rating $+\beta_{5}$ Interest $+\beta_{6}$ Duration $+\beta_{7}$ Ln Amount + $\beta_{8}$ Age $+\beta_{9}$ Income $+\beta_{10}$ Educational Attainment 
where (2) is the main outcome equations and (1) is the sample selection equation. We use a Maximum Likelihood estimator to estimate (1) and (2) simultaneously.

The dependent variable of (2) is a dummy variable taking the value of one if the loan application is successful and zero otherwise. Trust is our key independent variable in the outcome equations. We use the STATA function ustrregexm to search for words in the project description that are associated with trust. The Chinese words we select are "chengshi" (honesty), "chengxin" (integrity), "kekao" (trustworthy), "xinyong" (credence), "kaopu" (reliable) and "xiangxin" (trust). If any of these words appear in the description of the project, the variable trust takes the value of 1; if none appears, it takes the value of zero ${ }^{7}$. Words of this kind are related to the drivers of 'cognition-based trust' as opposed to that of 'affective-based trust' (e.g. mutual understanding or personal relationship) (McAllister, 1995). McAllister (1995) found that cognition-based trust is a precursor to the development of affective-based trust. Besides, in an exploratory study examining how Chinese entrepreneurs perceive trust, Tan and Chee (2005) found that the use of words such as 'honest', 'integrity', 'sincerity', 'discreetness' and 'fairness' facilitated the development of trust among Chinese entrepreneurs.

The credit rating assigned by the platform is another independent variable. We code 0 for HR, 1 for E, 2 for D, 3 for C, 4 for B, 5 for A, and 6 for AA. If H1 holds, then the coefficients associated with the variable trustworthiness will be positive and significant. To test $\mathrm{H} 2$, we use a similar specification, but we interact the variable Trust with the applicant's credit rating (as assigned by the platform); if $\mathrm{H} 2$ holds, the coefficient $\beta_{3}$ and $\beta_{3}$ will be simultaneously positive and significant.

\footnotetext{
${ }^{7}$ This procedure differs from the one described by Defazio et al. (2020) and relies on a deductive approach to the identification of trust-related words. The length of the text and the fact that the projects are written up in Chinese, implies that we cannot use the tools used by Defazio et al. (2020) in their paper. However, a more elaborate procedure that includes some of the steps suggested by Defazio et al. (2020) to identify the "sentiment" expressed by the projects' description in our sample is presented in the section on robustness tests.
} 
To be able to identify the selection equation (Pham and Talavera, 2018), we create a new variable (Branch) which is equal to one if an offline branch is located in the same city as the borrower and zero otherwise. This is also a proxy for financial accessibility. We conjecture that borrowers prefer an offline check if there is an offline branch located nearby because by doing so, the chances of the project being funded increase while incurring in a negligible additional cost (Tao et al., 2017). Other variables include the presence of a mortgage (1/0), car loan (1/0), age, income, and educational qualifications. The first two variables are proxies for the presence of collateral which may be associated with the likelihood of being funded. Conversely, this empirical specification suggests that borrowers with no mortgage and no car loan cannot have access to loans.

Additional control variables include the number of words used to describe the project, applicants' educational attainment, their age, loan amount, loan duration, and their monthly income as reported in the listing. A long text is considered to be a signal of openness and transparency from the borrowers' end of the transaction, and therefore we expect that lenders are willing to fund loans that are well described and articulated (Dorfleitner et al., 2016). However, if the description of the project is too wordy, the investors may not have enough patience to go through all the text. Taken together, we expect a positive association between the number of words and investors' actions. Income is a categorical variable taking values between 0 and 6 while Educational attainment proxies for the educational attainment of the applicant and ranges between 0 and 3. Finally, NonOffline is a dummy variable that takes the value of 1 if the listing has not been verified through the offline authentication and 0 otherwise.

Among the listings that were not funded, $22 \%$ of the descriptions contain words that are related to trust while the proportion goes down to $3 \%$ for the projects that were funded. The 
length of the description of the projects varies among groups of projects: the average length of the non-funded projects is equal to 58 words while this goes up to 110 words among the funded projects. Interest rates for the two groups of projects tend to be different although they are above 10\%: more accurately they are equal to $12.6 \%$ (on average) for the projects that were not funded and $11.4 \%$ for the projects that were. Credit ratings for projects that have not been funded are on average equal to HR while these go up to B for projects that have been funded. Virtually no funded project has been authenticated offline, while around $71 \%$ of the funded projects have been authenticated offline. On average, funded projects are smaller than non-funded projects: the average amount of the loan varies between the two groups: it is equal to around 86500RMB for non-funded projects, but it is equal to 59492RMB for the funded ones. The average proposed duration of the non-funded projects is 20 months while this goes up to 25 months for the funded projects. There is no difference between the two groups of projects in terms of the applicants' average income: it is between 5000 and $10000 \mathrm{RMB}$ for both groups of projects.

Table 1 describes the variables, while the descriptive statistics are listed in Table 2.

Table 3 reports the Pearson's correlation coefficients among the variables. These are generally significant while on average, the value of the coefficients is not above 0.7 , suggesting they can be used in the same model.

--- INSERT TABLE 1 ---

--- INSERT TABLE 2 ---

--- INSERT TABLE 3 --- 
We also check the multicollinearity among the independent variables using the VIF test (see table 3a): the average VIF is 2.24 and the maximum VIF is 6.5 (well below the value of 10). In other words, the results show no sign of multicollinearity among the independent variables.

\section{--- INSERT TABLE 3a ---}

\section{Results}

Table 4 shows the estimates of the marginal effects for the selection equation (1). Model 1 is our baseline model: the independent variables include an offline branch dummy, Branch, as well as other variables such as Mortgage and Car loan. Model 2 introduces the borrowers' demographic characteristics such as Age, Income, and Educational attainment.

\section{--- INSERT TABLE 4 ---}

The estimates suggest that applicants prefer offline authentication to the online one if a branch is located in their city and whether they have credit history and some potential collateral. From Model 2, we gather that young applicant are less likely to opt for offline verification while educational attainment is not a significant variable. Applicants with higher incomes are more likely to opt out of offline authentication. The value of the Chi-square $(-3037.42, \mathrm{p}<0.01)$ suggests that Model 2 is preferable to Model 1. Hence, we use Model 2 as our preferred specification of the selection equation. 
Table 5 reports the marginal effects of (2). Generally speaking, the two-step Heckman model is well-suited for our purpose as the p-value of the Wald test is less than 0.05 across all specifications. Model 1 consists of only three key independent variables, while Model 2 and Model 3 add to the regressors demographic and listings' characteristics, respectively. Finally, we add an interaction term between the variable Trust and the credit rating indicator to test whether the two types of signals are complementary or substitute (Model 4). The marginal effects associated with the variable Trust are positive and significant across Model (1)-(3) and in general, they support H1a. In other words, applicants who use words that are associated with trust tend to be funded. When the variable Trust interacts with the Credit Rating variable (Model 4), the marginal effect of the interaction (calculated manually using STATA ${ }^{8}$ ) is positive and significant although the variable Trust in level is no longer significant. The sign of the marginal effect associated with the interaction term suggests there exists a net positive association between the credit rating indicator and funding success among borrowers for whom the values of the trust variable are equal to 1 (confirming H2a). Separately, we have tested whether the variable Credit Rating is still significant when the variable Trust is equal to one, and we find this is the case. This suggests that borrowers who do not choose offline authentication can frame their message in such a way they elicit sentiments of trust and trustworthiness among potential lenders; then, all things being equal, they are more likely to be funded and the probability of receiving a loan increases by $10 \%$. Natural logarithm of the number of words used to describe the project (LnWordCount) is positive and significant across all specifications.

\section{--- INSERT TABLE 5 ---}

\footnotetext{
${ }^{8}$ The STATA command suggested by Norton et al. (2004) cannot be applied to the Heckman Probit model we estimate in the paper.
} 
Demographic variables, Age and Educational attainment, are in general positive and significant (Tao et al., 2017). The older the applicant and the more qualified it is, the more likely he is to be funded. In terms of the other control variables, the requested amount of the loan is negatively associated with funding success. Income is significant in Model 3 and 4 only, but it has a positive sign suggesting that applicants who claim to receive a more substantial income are more likely to have their projects funded. Variables associated with the characteristics of the listings (such as Interest rate, Months and LnAmount), are highly significant, and the signs of the marginal effects are in line with our expectations. Higher interest rates attract lenders and increase the probability of funding success. LnAmount is negative and significant, implying that P2P investors tend to prefer small loans so to diversify the risk. When the loan amount increases, lenders are suspicious about the borrowers' ability to repay the loan; therefore, this decreases the probability of funding success (Herzenstein et al., 2008). Unlike previous papers (see, for instance, Tao et al., 2017), we find that the proposed loan duration is negatively associated with funding success, suggesting lenders perceive long-term loans to be risky. Finally, we plot the probability of being funded against the different values of the Credit Rating variable under the two values of the variable Trust (Figure 3). Ceteris paribus, the probability of being funded is lower when the variable Trust is equal to 0 than otherwise for each value of the Credit Rating variable. The only exception is for the highest values of the Credit Rating, where the two probabilities coincide. 


\section{Robustness Check}

\subsection{Sentiment Analysis}

Sentiment analysis can identify and mine positive/negative opinions and emotions that are derived from the text (Wilson et al., 2005). The words in the project's description may contain both positive and negative sentiments. Since the focus of this study is on message framing, an interesting robustness test is to apply sentiment analysis to the projects' descriptions and use the findings to test for the robustness of the main results (Zuo et al., 2019). Following Zuo et al. (2019), Guo et al. (2019), and Zhang et al. (2017), we use SnowNLP, a Chinese natural language processing library in Python, for our sentiment analysis. This library has similar functions as TextBlob (a Python library for English textual data), such as word segmentation, part-of-speech tagging, text abstraction, and sentiment analysis. For each loan description, SnowNLP can predict the sentiment orientation of the text by a built-in Chinese dictionary. The dictionary has been constructed by SnowNLP developers ${ }^{9}$ They collect sentences from microblogs and online reviews and define these sentences as positive or negative languages. The precision rate of SnowNPL is over $80 \%$ (Zhang et al., 2018). Although SnowNLP allows users to apply their dictionaries, we choose to use a built-in dictionary to eliminate the potential self-selection bias derived from using a self-chosen dictionary ${ }^{10}$ Besides, as online words have unique features ${ }^{11}$, SnowNLP's built-in dictionary is well-suited for our analysis. The algorithm used by SnowNLP is a Naive Bayes algorithm, a probability model for binary classification. Hence, the SnowNLP output indicator is a value between 0 (negative emotion) and 1 (positive emotion). For example,

\footnotetext{
${ }^{9}$ For an open-source Python package in sentiment analysis, see https://github.com/isnowfy/snownlp for details. The positive/negative language dictionaries and detailed codes to calculate sentiment index are public on the developers' website.

${ }^{10}$ This approach is quite different from the one adopted for the primary analysis. In that case, trust-related words have been identified using a deductive approach (see Defazio et al., 2020, for more details).

${ }^{11}$ Yang (2007) suggests the writing style of internet communities is different from other writing styles. For example, huichang (灰常) is for feichang (非常), which means “very much”.
} 
one description is as follows "I found an investment opportunity, so I need funding. My monthly income is RMB 3000. I have a house and good borrowing history. I will use my salary and the return from the investment to pay back the loan." The valued returned by SnowNLP is 0.999, implying that the text evaluated is exceptionally likely to be positive.

How does SnowNLP treat negative prefixes which can alter the meaning of a positive word? To test how the library is dealing with these cases, we have run two tests. We use two loan descriptions to show how SnowNLP calculates the sentiment index in a text with a negative prefix before positive words. The first description is as follows: "I have some spare time after work so I would like to apply for my first loan here to do some small business. I have no idea whether it is trustworthy or not trustworthy (NT: in English, we may omit last trustworthy but in Chinese, we keep it) so I just try a small amount of money. I am working at Changsha and have bought a 150 square feet flat in my hometown." In this case, the returned index is 0.37 suggesting that the sentiment conveyed by the description of the applicant's situation is not that positive.

Consider now the following text: "I am a civil servant, working at local Justice Bureau and I am deputy head of the department. I have a stable job with a monthly income of RMB 8000. I don't have bad habits. The purpose of this loan is to invest in a shop but there is not enough money. I am a trustworthy person and a veteran cadre at my workplace. I can make sure to repay the loan on time". The returned index is 0.97 as the tone of the description is generally positive. The conclusion is that SnowNLP can identify a negative prefix in a text and correctly interpret the sentiment conveyed by a text. 
We apply SnowNLP to our dataset and Table 6 shows the results of the analysis. The sentiment score is a continuous variable, predicted by SnowNLP directly. The sentiment score is added to our empirical specifications (1)-(3), and the marginal effects are presented in Table 6. In Model (1), the sentiment score is added directly to (2) and (3); the results suggest the score is positively associated with the probability of being funded although when the interaction is introduced in the model, the variable is no longer significant. Next, we transform the sentiment score into many dummy variables. Following Zhang et al. (2017)'s procedure, we decide that if the value of the indicator is larger than 0.6 , the sentiment conveyed by the description is positive. When the sentiment score is lower than 0.6 , the sentiment is neutral or negative. So, we define a dummy variable (Sentiment06), which equates to one if the value of the sentiment score is above 0.6 and 0 otherwise. Model (3) and (4) show the results of Sentiment0.6 and its interaction term with CreditRating, respectively. Both are positive and significant at 5\% level. Similarly, we define another dummy variable taking the value of one if the value of the sentiment score is above 0.7 and 0 otherwise. The results of the new empirical specifications, which include the new dummy variable are shown in Model (5) and Model (6) and are qualitatively the same as the main results presented above.

\section{--- INSERT TABLE 6 ---}

\subsection{Subsample Analysis}

To further check the robustness of our main findings, we divide our sample into two subsamples based on borrowers' locations, i.e. the coastal region and the rest of China, and rerun our models for these two sub-samples. The coastal regions (Heibei, Beijing, Tianjin, 
Shandong, Jiangsu, Zhejiang, Shanghai, Guangdong, Hainan, and Fujian), are considered to be China's growth hub as opposed to the other regions. As a result, institutions in the coastal region that co-evolve with the development of the market-oriented economy are better developed than in other regions. The sub-sample analysis thus allows for the assessment of the impact of a positively framed message in various institutional environments.

The results are shown in Table 7. The model (1) and (2) refers to the coastal provinces subsample. The marginal effect associated with the critical variable (Trust) is now not significant, while the interaction term is positive and significant. The results for the non-coastal provinces sub-sample are shown in Models (3) and (4). Both variables are now positive and significant for this sample. The results in Table 7 indicate that a positively framed message has a direct effect on funding success in non-coastal regions but not in the coastal region and that a positively framed message has a complementary effect on funding success in both coastal and non-coastal regions. These results are interesting as they provide new insights into the effect of message framing in different settings of the institutional environment. In Zhang and Ke's (2003) research on trust and its sources in Chinese regions, they find that trust is closely related with regional institutional developments; they also find that trust between regions is not reciprocal in the sense that people from less developed regions place more trust in those from developed regions than the perceived trust they receive from the latter. This implies that despite the overall low trust culture, as observed in China, trust culture varies across regions. Hence, relatively speaking, borrowers from the coastal region feel less compelled than their counterparts in other regions to use message framing to convey a sense of trustworthiness. By the contrary, lack of reciprocal trust means that borrowers from non-coastal regions see greater need to use more means to convey the sense of trustworthiness, including message framing. This may explain why we only 
observe a significant relationship between a positively framed message and funding success in non-coastal regions. Nonetheless, investors would still appreciate the additional information that adds context to interpret credit scores.

\section{--- INSERT TABLE 7 ---}

\subsection{Alternative Measures of Funding Outcomes}

Alternative measures of funding outcomes include the number of bids that a project receives; this is an indicator which is potentially correlated with funding success as a project which receives a large number of bids is more likely to be funded as well. Therefore, in the last batch of robustness tests, we test whether message framing matters for the number of bids associated with each project. The dependent variable is the number of bids a project gets; this is proxied by the number of lenders who bid in each campaign. Empirically, the model is similar to the one estimated above although the dependent variable is now a continuous one (i.e. not a dummy variable) and therefore a standard Heckman model is estimated. The results are presented in Table 8. Our key independent variables (jointly with the interaction term) are not significant, suggesting that $\mathrm{H} 1 \mathrm{~b}$ and $\mathrm{H} 2 \mathrm{~b}$ are not verified.

\section{--- INSERT TABLE 8 ---}

\subsection{When Less Is More}

For our primary empirical analysis, we have focused on the impact that the presence of trustrelated cues has on a project's funding outcome, andwe use a dummy variable to capture whether 
or not a trust-related cue presents in the project description. The literature on message framing highlights that too many cues may obscure the message and therefore have a negative impact on the audience. For instance, Parhankangas and Ehrlich (2014) find that the use of overly positive language among startups is inversely correlated to business angels' financial support. To test whether this is the case in the context of P2P lending, we have created two new variables: CountTrust and CountTrust Square. CountTrust is the number of trust-related words appeared in the borrower's description. CountTrust Square is the square term of CountTrust. We then reestimate the primary model. The results as presented in Table 9 show that the marginal effect associated to the first variable is positive and significantly associated to a positive funding outcome; however, this is no longer true in the case of the second variable. CountTrust Square is negative and significant. Hence, the relationship between funding success and the number of trust-related words are inverted $U$ shape. The results support the notion that "one or two references might be enough to set the frame for a large amount of context" (Hertog and Mcleod, 2001, p.152). The findings imply that over-emphasizing a frame is probably less useful (Defazio et al., 2020).

--- INSERT TABLE 9 ---

\section{Discussion}

\subsection{Theoretical Implications}

The findings of this study demonstrate that a positively framed message is positively associated with funding success in the context of $\mathrm{P} 2 \mathrm{P}$ lending. Our results reconcile contrasting 
findings in the context of online reviews (e.g. Ludwig et al., 2013; Salehan and Kim, 2016) by showing that message framing matters in the case of Internet-mediated transactions. Theoretically, we have combined message framing theory with signalling theory to show that language used through message framing can be a powerful signalling device even if the message is mediated by technological devices (like platforms or online sites).

Our findings are also consistent with research in marketing which has shown that message framing has a much stronger effect when consumers have little or no related product experience (Chang, 2007). Once translated to our context, our findings imply that message framing can be useful when investors have no familiarity with potential borrowers listing their projects on a platform. Besides, our study contributes to the literature on low-cost signals and external funding (e.g. Chen et al., 2009). In the P2P lending context, investors may not be able to assess the highcost signals transmitted by the borrowers. Therefore language may be an essential signal (although low cost or cheap) in P2P lending decisions unlike what we would expect in the light of traditional signalling theory suggesting that low-cost signals do not allow to separate between different types of borrowers (Balvers et al., 2014). Cheap or low-cost signals enhance these benefits by providing a valid form of communication between entrepreneurs and funders (Davis and Allison, 2013). Such communication is particularly important in virtual environments with no face-to-face interactions.

While some studies suggest that observable actions (i.e. costly signals) are the more credible signalling mechanism compared to cheap talk (Cheung et al., 2014), our findings show that high cost and low-cost signals complement each other. Therefore they contribute to the literature examining the interaction between different signals on aggregate outcomes (Anglin et al., 2018). The high-cost signals reduce the risks of cheating and any costs associated with 
misleading signals (Connely et al., 2011). However, the costs of relying exclusively on high-cost signals and assessing them may be high. As such, the complementary use of low-cost signals may be more cost-effective for senders of such signals.

\subsection{Implications for Practitioners}

This study suggests that message framing as a low-cost signal can be useful in enhancing the likelihood of a project being funded. Potential borrowers signalling messages for P2P lenders need to frame their messages with words such as honesty, integrity, credence, and reliable, which signal their trustworthiness quality. Besides trustworthiness, potential borrowers can also display other qualities through language to attract investors and increase the potential for funding success. For example, signalling words associated with the agility, proactiveness, ambiguousness, empathy, and network size of a potential borrower may support lenders' decisions on whether the borrower is worth investing. In this sense, message framing can be very relevant. Claeys and Cauberghe (2014) suggest that in high involvement situations, decisionmakers generate counterarguments when a persuasive message is unconvincing. Since P2P lending involves a high involvement decision, language signalling messages about borrowers need to be presented in a convincing way to the lenders. In this sense, the use of right words reflecting the trustworthiness as the crucial quality of a borrower and how the message is framed to persuade the lenders would be highly significant. Using positive language to emphasize the cognitive and emotional states of a borrower's trustworthiness will enhance the odds for funding success.

Furthermore, as suggested by our findings, to enhance the odds of funding success, highcost signals such as information on the credit rating of a potential borrower can be 
complemented by suitably framed messages embedded in the description of the project. This is because, when a borrower communicates their credit rating through objectively assessed evidence, their continuous emphasis on their credit history may only have a supplementary role, and thus have an additional marginal influence on their funding success. If borrowers seeking funds can enhance their communication mode through the use of positive messages, their qualities, which can be objectively assessed, would be supported through language, and therefore increase the likelihood of being funded.

\section{Conclusion and Future Research}

This study has examined the role of message framing in the context of P2P lending. The study has confirmed that positive message framing is associated with funding success. The study also found that low-cost message framing and high-cost signals (like credit ratings) complement each other. This research has only focused on how message framing through language as a lowcost signal can enhance funding success in the context of P2P lending. Future studies can focus on how message framing can be complemented by other types of low-cost signals such as writing style (Li and Zhan, 2011). Besides, this study only examined the role of message framing as a low-cost signal that can motivate investors to fund the project. Future research can investigate whether negative language may attract the attention of investors and how it may affect their decisions. Specifically, future studies can use sentiment analysis to understand how creating negative emotions about the competing actors may affect a borrower's success in obtaining funds. For example, studies can investigate whether spillovers of messages explaining the risks of funding may be perceived to be a negative message and thus can impact the odds of finding success across several platforms. 
Future research can use a multi-level study to analyze how individual-related and environmental issues, from both borrower and investor perspective, may affect the funding performance of potential borrowers. Finally, this study only focused on the extent to which message framing may moderate the effect of the credit rating on their funding success of a project. Future studies can investigate the moderating effects of other types of low-cost signals such as the entrepreneurship orientation of a borrower. An important issue to highlight here is the extent to which these results can be generalized to other platforms and more importantly, whether it is possible to conduct similar studies that use data from different platforms. Crucially, P2P platforms in China use different business models (e.g. pure online or a mix of online and offline business models) and in this respect merging data from several platforms cannot offer useful insights as in reality the data generating processes are different because of the way the platforms are run. In this respect, a useful exercise is not so much to increase the volume of data analyzed by merging different datasets but to ascertain whether, in platforms with different business models, message framing is as necessary as in the Renrendai platform.

\section{References}

Ahlers, G. K.C., Cumming, D., Günther, C., \& Schweizer, D. (2015). Signaling in Equity Crowdfunding. Entrepreneurship Theory and Practice, 39(4), 955-980.

Aktas, N., De Bodt, E., Bollaert, H., \& Roll, R. (2016). CEO narcissism and the takeover process: From private initiation to deal completion. Journal of Financial and Quantitative Analysis, 51(1), 113-137.

Andres, C., Betzer, A., \& Limbach, P. (2014). Underwriter reputation and the quality of certification: Evidence from high-yield bonds. Journal of Banking \& Finance, 40, 97-115. 
Anglin, A.H., Short, J.C., Drover, W., Stevenson, R.M., McKenny, A.F., \& Allison, T.H. (2018). The power of positivity? The influence of positive psychological capital language on crowdfunding performance. Journal of Business Venturing, 33(4), 470-492.

Audi, R., Loughran, T., \& McDonald, B. (2016). Trust, but verify MD\&A language and the role of trust in corporate culture. Journal of Business Ethics, 139(3), 551-561.

Avey, J. B., Reichard, R. J., Luthans, F., \& Mhatre, K. H. (2011). A meta-analysis of the impact of positive psychological capital on employee attitudes, behaviours, and performance. Human resource development quarterly, 22(2), 127-152.

Bachmann, A., Becker, A., Buerckner, D., Hilker, M. K. M., Lehmann, M., \& Tiburtius, P. (2011). Online peer-to-peer lending-a literature review. Journal of Internet Banking and Commerce, 16(2), 1-18.

Besharat, A. (2010). How co-branding versus brand extensions drive consumers' evaluations of new products: A brand equity approach. Industrial Marketing Management, 39, 1240-1249.

Bergh, D. D., Connelly, B. L., Ketchen Jr, D. J., \& Shannon, L. M. (2014). Signalling theory and equilibrium in strategic management research: An assessment and a research agenda. Journal of Management Studies, 51(8), 1334-1360.

Boyreau-Debray, G., \& Wei, S. J, (2005). Pitfalls of a state-dominated financial system: The case of China (No. w11214). National Bureau of Economic Research.

Breuer, W., Knetsch, A., \& Salzmann, A.J. (2018). What does it mean when managers talk about trust?. Journal of Business Ethics, 1-16.

Bruton, G., Khavul, S., Siegel, D., \& Wright, M. (2015). New financial alternatives in seeding entrepreneurship: $\quad$ Microfinance, crowdfunding, and peer-to-peer innovations. Entrepreneurship Theory and Practice, 39(1), 9-26. 
Chang, C-T. (2007). Health-Care Product Advertising: The Influences of Message Framing and Perceived Product Characteristics. Psychology \& Marketing, Vol. 24(2), 143-169.

Cheung, C. M.K., Xiao, B. S., \& Liu, I. B. (2014). Do actions speak louder than voices? The signalling role of social information cues in influencing consumer purchase decisions. Decision Support Systems, 65, 50-58.

Claeys, A-S., \& Cauberghe, V. (2014). What makes crisis response strategies work? The impact of crisis involvement and message framing. Journal of Business Research, 67, 182-189.

Connelly, B. L., Certo, S. T., Ireland, R. D., \& Reutzel, C. R. (2011). Signalling Theory: A Review and Assessment. Journal of Management, 37(1), 39-67.

Chen, X. P., Yao, X., \& Kotha, S. (2009). Entrepreneur passion and preparedness in business plan presentations: a persuasion analysis of venture capitalists' funding decisions. Academy of Management Journal, 52(1), 199-214.

Courtney, C., Dutta, S., \& Li, Y. (2017). Resolving information asymmetry: Signaling, endorsement, and crowdfunding success. Entrepreneurship Theory and Practice, 41(2), 265290.

Danilov, A., \& Sliwka, D. (2016). Can contracts signal social norms? Experimental evidence. Management Science, 63(2), 459-476.

Davis, B. C., \& Allison, T. H. (2013). Crowdfunding of entrepreneurial ventures: a comparison of signalling and impression management. Academy of Management Proceedings, 23 Feruaryb 2018.

Dorfleitner, G., Priberny, C., Schuster, S., Stoiber, J., Weber, M., de Castro, I., \& Kammler, J. (2016). Description-text related soft information in peer-to-peer lending - Evidence from two leading European platforms. Journal of Banking \& Finance, 64, 169-187. 
Dowell, D., Morrison, M. \& Heffernan, T. (2015). The changing importance of affective trust and cognitive trust across the relationship lifecycle: A study of business-to-business relationships. Industrial Marketing Management, 44, 119-130.

Duarte, J., Siegel, S., \& Young, L. (2012). Trust and Credit: The Role of Appearance in Peer-topeer Lending. The Review of Financial Studies, 25(8), 2455-2484.

Dyer, J. H., \& Chu, W. (2003). The Role of Trustworthiness in Reducing Transaction Costs and Improving Performance: Empirical Evidence from the United States, Japan, and Korea. Organization Science, 14(1), 57-68.

Davis, B. C., Hmieleski, K. M., Webb, J. W., \& Coombs, J. E. (2017). Funders' positive affective reactions to entrepreneurs' crowdfunding pitches: The influence of perceived product creativity and entrepreneurial passion. Journal of Business Venturing, 32(1), 90-106.

Defazio, D., Franzoni, C. and Rossi-Lamastra, C., (2020), How Pro-social Framing Affects the Success of Crowdfunding Projects: The Role of Emphasis and Information Crowdedness, Journal of Business Ethics, online accepted version.

Ding, R. \& Hou, W. (2015). Retail investor attention and stock liquidity. Journal of international financial markets, institutions and money, 37, 12-26.

Dorfleitner, G., Priberny, C., Schuster, S., Stoiber, J., Weber, M., De Castro, I. \& Kammler, J. (2016). Description-text related soft information in peer-to-peer lending - Evidence from two leading European platforms. Journal of Banking \& Finance, 64, 169-187.

Duan, T., Ding, R., Hou, W. \& Zhang, J. Z. (2018). The burden of attention: CEO publicity and tax avoidance. Journal of Business Research, 87, 90-101.

Eisend, M. (2009). A meta-analysis of humour in advertising. Journal of the Academy of Marketing Science, 37, 191-203. 
Engelberg, J. \& Gao, P. (2011). In search of attention. The Journal of Finance, 66, 1461-1499.

Farrell, J., \& Rabin, M. (1996). Cheap talk. Journal of Economic Perspectives, 10(3), 103-118.

Fukuyama, F. (1995). Trust: The Social Virtues and the Creation of Prosperity. The Free Press.

Fungacova, Z. and Weill, L., 2014. A view on financial inclusion in Asian countries. BOFIT Policy Brief, 2014(8), p.3.

Gao, H., Yu, T., \& Cannella Jr, A. A. (2016). The use of public language in strategy: A multidisciplinary review and research agenda. Journal of Management, 42(1), 21-54.

Guo, M., Liao, X., Liu, J., \& Zhang, Q. (2019). Consumer preference analysis: A data-driven multiple criteria approach integrating online informatio-Omega, in press.

Guo, Y., Zhoub, W., Luo, C., Liu, C., \& Xiong, H. (2016) Instance-based credit risk assessment for investment decisions in P2P lending. European Journal of Operational Research 249, $417-426$.

Han, J. T., Chen, Q., Liu, J. G., Luo, X. L., \& Fan, W. (2018). The persuasion of borrowers' voluntary information in a peer to peer lending: An empirical study based on the elaboration likelihood model. Computers in Human Behavior, 78, 200-214.

Harmon, D. J., Green Jr, S. E., \& Goodnight, G. T. (2015). A model of rhetorical legitimation: The structure of communication and cognition underlying institutional maintenance and change. Academy of Management Review, 40(1), 76-95.

Hasan, A., Moin, S., Karim, A., \& Shamshirband, S. (2018). Machine learning-based sentiment analysis for twitter accounts. Mathematical and Computational Applications, 23(1), 11.

Heckman, J.J. (1979). Sample selection as a specification error. Econometrica, 47, 153-161.

Hertog, J. K., \& McLeod, D. M. (2001). A multiperspectival approach to framing analysis: A

field guide. In S. D. Reese, O. H. Gandy, \& A. E. Grant (Eds.), Framing public life: Perspectives 
of media and our understanding of the social world (pp. 139-161). New York: Routledge. https://doi.org/10.4324/9781410605689

Herzenstein, M., Sonenshein, S., \& Dholakia, U. M. (2011). Tell me a good story and I may lend you money: The role of narratives in peer-to-peer lending decision-Journal of Marketing Research, 48, S138-S149.

Herzenstein, M., Andrews, R. L., Dholakia, U. M., \& Lyandres, E. (2008). The democratization of personal consumer loans? Determinants of success in online peer-to-peer lending communities. Boston University School of Management Research Paper.

Homer, P. M., \& Yoon, S. G. (1992). Message Framing and the Interrelationships Among AdBased Feelings, Affect and Cognition. Journal of Advertising, 21(1), 19-33.

Hoefer, R. L., \& Gree,n Jr, S. E. (2016). A rhetorical model of institutional decision making: The role of rhetoric in the formation and change of legitimacy judgments. Academy of Management Review, 41(1), 130-150.

Hsu, P.Y., Lei, H.T., Huang, S.H., Liao, T.H., Lo, Y.C., \& Lo, C.C., 2019. Effects of sentiment on recommendations in social network. Electronic Markets, 29(2), 253-262.

Huang, R. H. (2018). Online P2P Lending and Regulatory Responses in China: Opportunities and Challenges. European Business Organization Law Review, 19(1), 63-92.

Ke, R., \& Zhang, W (2003). Trust in China: A cross-regional analysis. William Davidson Institute Working Paper Number 586, William Davidson Institute, The University of Michigan Business School.

Kromidha, E., \& Robson, P. (2016). Social identity and signalling success factors in online crowdfunding. Entrepreneurship \& Regional Development, 28(9-10), 605-629. 
Krugman, D. M., Fox, R. J., Fletcher, J. E., Fischer, P. M., \& Rojas, T. H. (1994). Do adolescents attend to warnings in cigarette advertising? An eye-tracking approach. Journal of Advertising Research, 34, 39-39.

Landström, H. (2017). Advanced Introduction to Entrepreneurial Finance. Edward Elgar Publishing.

Lee, H-H. M, \& va,n Dolen, W. (2015). Creative participation: Collective sentiment in online cocreation communities. Information \& Management, 52, 951-964.

Lee, R.P., Chen, Q., \& Hartmann, N. N. (2016). Enhancing Stock Market Return with New Product Preannouncements: The Role of Information Quality and Innovativeness, Journal of Product Innovation Management, 33(4), 455-471.

Li, J., \& Zhan, L. (2011). Online Persuasion: How the Written Word Drives WOM: Evidence from Consumer-Generated Product Reviews.Jjournal of Advertising Research, 51(1), 239-57.

Lin, M., Prabhala, N. R., \& Viswanathan, S. (2013). Judging borrowers by the company they keep: Friendship networks and information asymmetry in online peer-to-peer lending. Management Science, 59(1), 17-35.

Liu, Y., Zhou, Q., Zhao, X., \& Wang, Y., 2018. Can listing information indicate borrower credit risk in online peer-to-peer lending? Emerging Markets Finance and Trade, 54(13), 2982-2994.

Loewenstein, G., Sunstein, C.R., \& Golman, R., 2014. Disclosure: Psychology changes everything. Annu. Rev. Econ., 6(1), 391-419.

Ludwig, S., de Ruyter, K., Friedman, M., Brüggen, E., Wetzels, M., \& Pfann, G. (2013). More than words: The influence of affective content and linguistic style matches in online reviews on conversion rates. Journal of Marketing, 77(1), 87-103. 
Luthans, F., Luthans, K. W., \& Luthans, B. C. (2004). Positive psychological capital: Beyond human and social capital. Business Horizons, 47(1), 45-50.

Maheswaran, D., \& Meyers-Levy, J. (1990). The Influence of Message Framing and Issue Involvement. Journal of Marketing Research, 27(3), 361-367.

Martens, M. L., Jennings, J. E., \& Jennings, P. D. (2007). Do the stories they tell get them the money they need? The role of entrepreneurial narratives in resource acquisition. Academy of Management Journal, 50, 1107-1132.

Martí, J., \& Balboa, M., 2007. Characterization of the reputation of private equity managers: Evidence in Spain. Journal of Business Venturing, 22(4), 453-480.

McAllister, D.J. (1995). Affect and cognition-based trust as foundations for interpersonal cooperation in organization-Academy of Management Review 20, 709-34.

McKenny, A. F., Allison, T. H., Ketchen Jr, D. J., Short, J. C., \& Ireland, R. D. (2017). How should crowdfunding research evolve? A survey of the entrepreneurship theory and practice editorial board. Entrepreneurship Theory and Practice, 41(2), 291-304.

Mi, J. J., \& Zhu, H. (2017). Can funding platforms' self-initiated financial innovation improve credit availability? Evidence from China's P2P market. Applied Economics Letters, 24, 396398.

Michels, J. (2012). Do unverifiable disclosures matter? Evidence from peer-to-peer lending. The Accounting Review, 87(4), 1385-1413.

Mittal, S., \& Lloyd, J. (2016). The rise of FinTech in China: redefining financial services. A Collaborative Report. DBS and Ernst \& Young (EY). https://www.ey.com/Publication/vwLUAssets/ey-the-rise-of-fintech-in-china/\$FILE/ey-therise-of-fintech-in-china.pdf (Accessed 4 January 2019). 
Newman, A., Ucbasaran, D., Zhu, F. E. I., \& Hirst, G. (2014). Psychological capital: A review and synthesis. Journal of Organizational Behavior, 35(S1), S120-S138.

Norton, E. C., Wang, H., \& Ai, C. (2004). Computing interaction effects and standard errors in logit and probit models. The Stata Journal, 4(2), 154-167.

Öhman, A., Flykt, A., \& Esteves, F. (2001). Emotion drives attention: detecting the snake in the gras- Journal of Experimental Psychology: General, 130(3), 466.

Pham, T., \& Talavera, O. (2018). Discrimination, social capital, and financial constraints: The case of Viet Nam. World Development, 102, 228-242.

Pieters, R. \& Wedel, M. (2004). Attention capture and transfer in advertising: Brand, pictorial, and text-size effects. Journal of Marketing, 68, 36-50.

Plummer, L. A., Allison, T. H., \& Connelly, B. L. (2016). Better together? Signalling interactions in new venture pursuit of initial external capital. Academy of Management Journal, 59(5), 1585-1604.

Putnam, R. (2000). Bowling Alone: The Collapse and Revival of American Community. New York: Simon \& Schuster.

Salehan, M., \& Kim, D.J. (2016). Predicting the performance of online consumer reviews: A sentiment mining approach to big data analytics. Decision Support Systems, 81, 30-40.

Salomon, V. (2018). Strategies of startup evaluation on crowd-investing platforms: The case of Switzerland. Journal of Innovation Economics Management, (2), pp.63-88.

Sparks, B., \& Browning, V. (2011). The impact of online reviews on hotel booking intentions and perception of trust. Tourism Management, 32(6), pp. 1310-1323.

Spence, M. (1973). Job Market Signaling. The Quarterly Journal of Economics, 87(3), 355-374. 
Steigenberger, N., \& Wilhelm, H. (2018). Extending Signaling Theory to Rhetorical Signals: Evidence from Crowdfunding. Organization Science, 29(3), 529-546.

Tan, H. H., \& Chee, D. (2005). Understanding interpersonal trust in a Confucian-influenced society: An exploratory study. International Journal of Cross-Cultural Management, 5(2), 197-212.

Tao, Q., Dong, Y. \& Lin, Z,. 2017. Who can get the money? Evidence from the Chinese peer-topeer lending platform. Information Systems Frontiers, 19, 425-441.

Wang, J., Shen, Y., \& Huang, Y., 2016. Evaluating the regulatory scheme for internet finance in China: the case of peer-to-peer lending. China Economic Journal, 9(3), pp.272-287.

Welter, F., \& Smallbone, D. (2006). Exploring the role of trust in entrepreneurial activity. Entrepreneurship Theory and Practice, 30(4), 465-475.

Wilson, T., Wiebe, J., \& Hoffmann, P, (2005). Recognizing contextual polarity in phrase-level sentiment analysis. In Proceedings of Human Language Technology Conference and Conference on Empirical Methods in Natural Language Processing.

Xu, J. J., \& Chau, M. (2018). Cheap talk? The impact of lender-borrower communication on peer-to-peer lending outcomes. Journal of Management Information Systems, 35(1), 53-85.

Xu, Q., Fernando, G.D., \& Tam, K, (2019). Trust and firm performance: A bi-directional study. Advances in Accounting, 47, p. 100433.

Yang, C, (2007). Chinese Internet language: A sociolinguistic analysis of adaptations of the Chinese writing system.Llanguag e@ internet, 4(2).

Yao, J., Chen, J., Wei, J., Chen, Y. \& Yang, S. (2018). The relationship between soft information in loan titles and online peer-to-peer lending: evidence from RenRenDai platform. Electronic Commerce Research, 1-19. 
Zhang, L., Li, X.P., Zhang, F.B. and Hu, B., (2017). Research on Keyword Extraction and Sentiment Orientation Analysis of Educational Texts. Journal of Computers, 28(6), pp.301313.

Zhang, S.T., Wang, F.F., Duo, F. and Zhang, J.L., 2018. Research on the Majority Decision Algorithm based on WeChat sentiment classification. Journal of Intelligent \& Fuzzy Systems, 35(3), pp.2975-2984.

Zhang, W., Ke, R., 2003. Trust in China: a cross-regional analysis. Economic Research, 8, pp.59-70.

Zhang, Y. and Buda, R. (1999). Moderating Effects of Need for Cognition on Responses to Positively versus Negatively Framed Advertising Messages. Journal of Advertising, 28(2), 115.

Zuo, W., Zhu, W., Chen, S. and He, X., 2019. Service quality management of online car-hailing based on PCN in the sharing economy. Electronic Commerce Research and Applications, 34, p.100827. 
